\title{
Corpos, significados e políticas lesbianas em Terra Molhada
}

Lesbian Bodies, Meanings, And Politics in Terra Molhada

Mônica Saldanha

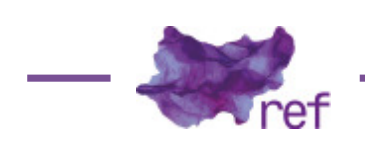

COELHO, Thalita.

Terra molhada.

São Paulo: Editora Patuá, 2018.

Poesia e lesbianidade têm uma longa história em comum: da mitológica Safo - cujos versos sobre o amor entre mulheres marcaram-na como símbolo da identidade lésbica - à escrita profundamente política de Audre Lorde - para quem a poesia não é um luxo, mas janela para um espaço de poder que repousa na profundidade de nossos afetos - a poesia lesbiana se firmou como instrumento de visibilidade e luta.

O silêncio marca a história da lesbianidade. Nossos corpos, olhares e existências foram, por muito tempo, registrados somente na sutileza das entrelinhas e, como sublinha Patrícia Lessa (2003), quando as palavras não circulam, não circulam também seus significados, produzem-se espaços de abjeção. Mais além, a narrativa oficial traz as cicatrizes de um o esforço produtor da lesbianidade com sentidos muito específicos: se não é a medicalizada homossexualidade feminina, é o que Tânia Navarro-Swain chamou "pasto para o olhar masculino" (NAVARRO-SWAIN, 2000 , p. 74). Não há nela espaço para os significados políticos da existência lesbiana.

Virgínia Leal (2016) relaciona a atuação de movimentos sociais à emergência e crescente visibilidade de produções literárias imbuídas de causa política - afastando-se do ideal estritamente estético que caracteriza a literatura como simples entretenimento - e, portanto, à constituição de um campo específico de literatura lésbica. A literatura lésbica é, na visão descrita por Lúcia Facco (2013 apud LEAL, 2016), uma tábua de salvação para aquelas cujo desejo é sistematicamente invisibilizado e cuja existência é definida como anormal.

Terra Molhada é o primeiro livro publicado por Thalita Coelho, doutoranda no Programa de Pós-Graduação em Literatura, na linha de pesquisa Crítica Feminista e Estudos de Gênero, da Universidade Federal de Santa Catarina. A obra não foge às influências dos estudos feministas, tampouco à tarefa de conferir visibilidade à literatura lésbica, convidando-nos sempre à identificação e à reelaboração, através de sua coletânea de poemas e prosas poéticas de temática inegavelmente lesbiana. Terra Molhada interage com outras expressões artísticas, trazendo ilustrações inspiradas por seus textos, e dialoga também com a dinâmica das redes sociais, como em "Sobre como lésbicas decidem com quem sair", no qual se resgatam estereótipos da identidade lésbica em tom divertido, questionando "será que eu adotaria um gato com essa pessoa?" (Thalita COELHO, 2018, p. 73). 
Thalita nos convida ainda à identificação ao expor os processos dolorosos de rejeição e confusão que marcam a experiência de descobrir-se dissidente da ordem heterossexual e de gênero, assim como a quase epifania do reencontro consigo mesma, do reivindicar-se politicamente e apropriar-se de sua agência como sujeito. O processo de transformação da dor - da vitimização - em potência transformadora, em estímulo para a luta, marca muitos dos textos e resgata um aspecto penoso da lesbianidade sem deixar-se definir por ele.

Contudo, a literatura lesbiana pode ser - e é - muito mais do que um porto seguro e um espaço de identificação coletiva, a escrita sapatão tem a faculdade de torcer significados e fazer aflorar novos olhares. Nas palavras de Lorde, "a poesia é a forma como nomeamos o inominável para que seja possível pensá-lo'" (2007a, p. 37, tradução nossa), um exercício de reelaboração do mundo a partir da mirada lesbiana, conforme proposto por Monique Wittig (1980), sempre presente no livro de Thalita Coelho.

Já nas primeiras páginas, Terra Molhada demonstra sua potência: dedicado às mulheres que amam mulheres, estende o significado do amor - rememorando o erótico feminino em Uses of the erotic de Lorde (2007b) - e, com isso, expande a experiência afetiva lesbiana ao indicar, lado a lado, namorada, avó e amiga. Anuncia-se a tônica do livro: a experiência lesbiana como experiência humana, complexa e múltipla, que renuncia às fronteiras determinadas do pensamento binário, recusando-se, contudo, a abdicar de sua especificidade e de sua relevância política.

Comprometida com a contingência e assumindo os riscos inerentes à transitoriedade da verdade, a eu-lírica lésbica de Thalita Coelho ora se alicerça em suas práticas sexuais, ora em seus desejos, ora em sua trajetória, ora em suas afinidades políticas, nunca perdendo de vista o viés feminista que carrega a afetividade como bandeira de luta, movendo-se entre os muitos entendimentos sobre o desejo e a sexualidade lesbiana.

Nesse exercício, Thalita brinca não só com o clichê da lésbica que odeia os homens, mas também com a viralidade dos memes, fenômeno marcante nas redes sociais, em construções como "a curva mais bonita de uma mulher / é a que ela faz na estrada / pra ir embora pra longe / de homens" (COELHO, 2018, p. 81). Em outros textos, a lesbianidade aparece como um santuário, um oásis e, ao focalizar a afetividade entre mulheres, desloca as fronteiras lesbianidade e recusa o referencial masculino:

Saída do canto, foi no encontro com outras línguas que eu mais aprendi sobre mim. Foi no estremecer de corpos que assimilei o ventre falante que reverberava, foi no mergulhar na umidade que me senti poliglota, foi no pronunciar de uma palavra que dominei o idioma e sorri junto ao espelho: lésbica (COELHO, 2018, p. 52).

A proposta feminista emerge, também, em "Mulher", em que, ao negar o contar-se em termos masculinos, reescreve a mulher por suas próprias palavras e denuncia os processos de exclusão que marcam o "masculino neutro" da linguagem. Implicitamente, a epistemologia feminista - e quiçá decolonial - deixa-se observar na escrita subjetiva, declaradamente imbricada em lutas políticas, na rejeição do ideal eurocêntrico de racionalidade e neutralidade - qualificado por Lorde (2007a) como estéril, insípido e carente de imaginação, que transforma a poesia em mero jogo de palavras. Os poemas de Thalita estão longe dessa espécie de parnasianismo masculino; são um manifesto sapatão. Entretanto, é no último poema que a resistência lesbiana emerge inequívoca: "minha maior luta é amar a céu aberto" (COELHO, 2018, p. 103) funciona tanto como declaração quanto como convite.

A característica mais marcante do livro talvez seja sua capacidade de, em seu tom confessional, atravessar os mais diversos aspectos da existência lesbiana sem, contudo, universalizála ou definir fundamentos absolutos. Por isso, ainda que seja impossível definir a lesbianidade a partir de um referencial inequívoco, conforme argumenta Navarro-Swain (1999), é seguro afirmar que Terra Molhada consegue bem representá-la.

\section{Referências}

COELHO, Thalita. Terra molhada. São Paulo: Editora Patuá, 2018.

LEAL, Virgínia Maria Vasconcelos. "Academia, criação literária e temática lésbica: a produção de Lúcia Facco". Estud. Lit. Bras. Contemp. [online], n. 47, p. 253-267, 2016. Disponível em: http:// dx.doi.org/10.1590/2316-40184712. Acesso em: 14/03/2018.

LESSA, Patrícia. "O que a história não diz não existiu: a lesbianidade em suas interfaces com o feminismo e a história das mulheres". Em tempos de histórias, Brasília, n. 7, p. 1-8, 2003.

LORDE, Audre. Poetry is not a luxury. In: LORDE, Audre. Sister Outsider: essays and speeches by Audre Lorde. Berkeley: Crossing Press, 2007a. p. 36-39.

\footnotetext{
1 "Poetry is the way we help give name to the nameless so it can be thought".
} 
LORDE, Audre. Uses of the erotic: the erotic as power. In: LORDE, Audre. Sister Outsider: essays and speeches by Audre Lorde. Berkeley: Crossing Press, 2007b. p. 53-59.

NAVARRO-SWAIN, Tânia. "Feminismo e lesbianismo: a identidade em questão". Cadernos Pagu, Campinas, São Paulo, n. 12, p. 109-120, 1999.

NAVARRO-SWAIN, Tânia. O que é lesbianismo? São Paulo: Brasiliense, 2000.

WITTIG, Monique. "The straight mind". Feminist Issues, v. 1, n. 1, p. 103-111, 1980.

Mônica Saldanha' (iD) 0000-0002-7126-3807

Mestranda no Programa de Pós-Graduação em Educação (linha de pesquisa Educação e Ciências Sociais: Desigualdades e Diferenças)

Pós-graduada lato sensu em Educação Sexual. Integra os grupos de pesquisa Sexualidade Humana (UNISAL/CNPq) e Estudos de Gênero, Educação e Cultura Sexual - EdGES (FEUSP/CNPq).

Universidade de São Paulo, Faculdade de Educação, Programa de Pós-Graduação em Educação Avenida da Universidade, 308, Butantã

05508-040 - São Paulo - SP - Brasil

+55 (011) 3091-3519-posfe@usp.br

saldanha.msp@usp.br

\section{COMO CITAR ESSE ARTIGO DE ACORDO COM AS NORMAS DA REVISTA}

SALDANHA, Mônica. "Corpos, significados e políticas lesbianas em terra molhada". Revista Estudos Feministas, Florianópolis, v. 27, n. 1, e56310, 2019.

\section{CONTRIBUIÇÃO DE AUTORIA}

Não se aplica

\section{FINANCIAMENTO}

Não se aplica

\section{CONSENTIMENTO DE USO DE IMAGEM}

Não se aplica

\section{APROVAÇÃO DE COMITÊ DE ÉTICA EM PESQUISA}

Não se aplica

\section{CONFLITO DE INTERESSES}

Não se aplica

\section{LICENÇA DE USO}

Este artigo está licenciado sob a Licença Creative Commons CC-BY. Com essa licença você pode compartilhar, adaptar, criar para qualquer fim, desde que atribua a autoria da obra.

\section{HISTÓRICO}

Recebida em 10/04/2018

Aceita em 30/06/2018 